\title{
Glass ionomer cement in otological microsurgery: experience over 16 years
}

\author{
F. Righini-Grunder $\cdot$ R. Häusler $\cdot$ S. Chongvisal • \\ M. Caversaccio
}

Received: 27 May 2014/Accepted: 30 August 2014/Published online: 10 September 2014

(C) Springer-Verlag Berlin Heidelberg 2014

\begin{abstract}
A retrospective evaluation of glass ionomer cement (GIC) in middle ear surgery with emphasis on short- and long-term safety was conducted at the tertiary referral center. GIC was applied between 1995 and 2006 in 444 patients in otologic surgery. Technical aspects, safety, benefits and complications due to GIC were analysed until 2011 (follow-up 5-16 years; mean 10 years). GIC was applied in stapes surgery (228 primary, 92 revisions), cochlear implants (108) and implantable hearing aids (7), ossiculoplasty (7), for coverage of opened mastoid air cells towards the external ear canal (1) and inner ear fistula closure (1). GIC turned out to be very handy in stapes surgery for optimal prosthesis fixation at the incus (260) and on the malleus handle (60) without complications. Results suggest that GIC may diminish the danger of incus necrosis in primary stapedotomy. In cochlear implants and implantable hearing aids, GIC was used for casing alone (74), casing and electrode fixation (27) and electrode alone fixation (14). Inflammatory reactions were observed in five cases $(4.3 \%)$, mostly after trauma. Broken cement fragments appeared to promote foreign body rejection. In seven cases an incudo-stapedial gap was repaired with GIC with
\end{abstract}

F. Righini-Grunder · R. Häusler · S. Chongvisal ·

M. Caversaccio

University Department of ENT, Head and Neck Surgery,

Inselspital, Bern, Switzerland

R. Häusler ( $₫)$

Medical Faculty, University of Bern, Otological Office

Tiefenauspital, 3004 Bern, Switzerland

e-mail: rudolf_haeusler@bluewin.ch excellent hearing gain; in three cases (43\%) revision surgery was needed due to cement breakage. In one case, GIC was applied for a watertight coverage of opened mastoid cells, and in the other for fistula closure of the lateral semicircular canal over cartilage, covered with bone pathé; follow-up was uneventful. Targeted use of GIC in middle ear surgery rarely poses problems. GIC cannot be used in neuro-otosurgery in contact with cerebrospinal fluid because of possible aluminium encephalopathy.

Keywords Glass ionomer cement - Stapes surgery · Cochlea implantation and implanted hearing aids .

Ossiculoplasty $\cdot$ Middle ear surgery

\section{Introduction}

History of GIC

Glass ionomer cement (GIC) was developed in the 1970s by the chemists Alan Wilson and Brian Kent. It's a polymer composite, resulting from a reaction between alkaline aluminium containing inorganic ionomer, glass particles, and an organic polyacrylic acid [1-3]. As an adhesive, it may bind with bone, metals, synthetic materials and ceramics. Furthermore, the cold binding, tissue protecting GIC is not prone to shrinkage during its curing phase.

GIC has been developed and is still widely used for dentistry as filling material, for correction of dental roots or crowns and because of an antibacterial effect by releasing fluoride in its binding phase. [4-6].

GIC was also tried in orthopaedic surgery for joint repair $[7,8]$. But it turned out to be less able to withstand mechanical loads than other cements and therefore more susceptible to trauma $[9,10]$. 
Use of GIC in otology

GIC has been applied in otology since 1989 [11]. It was employed in stapes surgery for additional fixation of the prosthetic loop and in ossiculoplasty for bridging discontinuities [12]. The cement was also used for fixation of casings and electrodes in cochlear implants and implanted hearing aids as well as in mastoid surgery $[13,14]$. For a time, GIC was utilised for direct closure of cerebrospinal fluid (CSF) fistulas and for reconstruction of skull defects, especially in neurinoma surgery $[15,16]$. However, two fatal cases of aluminium encephalopathy have been reported $[17,18]$ and it was shown that GIC cannot harden and might release toxic aluminium ions when in contact with CSF [19, 20]. Subsequently, GIC became prohibited in neuro-otological surgery and the then used product Ionos ${ }^{\circledR}$ was withdrawn from the market. Most ear surgeons stopped any application of this adhesive in otology. Only in recent years a certain revival of the use of glass ionomer in middle ear surgery can be observed.

GIC application in middle ear surgery in Bern

In Bern, GIC has been used in middle ear surgery from 1992 at the University Department of ENT, Head and Neck Surgery, mainly in stapes surgery, cochlear implants, hearing aid implants and in a few cases of ossiculoplasty and mastoid surgery. It was never utilised in neuro-otological procedures associated with flow of CSF.

\section{Objective of the study}

The present study provides a retrospective evaluation of all patients in which GIC was applied in otology between January 1995 and March 2006. Technical aspects, safety and benefits as well as side effects and complications were registered and analysed in 2011. The study is based on inspection of medical files and history, films and pictures and personal follow-ups of included patients.

\section{Patients, interventions and GIC application technique}

Patients and interventions

GIC was applied for otological interventions in 444 patients, as shown in Table 1

Application technique of GIC

We mostly used the GIC SerenoCem ${ }^{\mathrm{TM}}$, approved for use in otology by EU, less frequently the much less expensive Ketac $\mathrm{Cem}^{\circledR}$ approved for dentistry. In both, GIC is packed sterile and provided in a bi-component capsule with two chambers. Once the surgeon is ready, both chambers are connected by breaking its separation. The capsule is shaken in a special device for $10 \mathrm{~s}$ for mixing the two components. Afterwards cement is pressed out and ready for use (Fig. 1). The cement must be applied within a few minutes on the field of operation. It is administered directly on bone and metal with a microtip (stapes surgery) or a small spatule. Contact with blood, fluid or soft tissue should be avoided as far as possible [17-20]. After a binding time of $10 \mathrm{~min}$, the cement becomes hard. Complete curing takes several hours.

\section{Results}

GIC in stapes surgery

GIC was used for stabilisation and optimal fixation of stapes prosthesis at the incus or the malleus handle. This

Table 1 Applications of glass ionomer cement, case numbers and gender

\begin{tabular}{|c|c|c|c|c|}
\hline & Female $(\mathrm{F})$ & Male (M) & Total & Age in years (range) \\
\hline Total number of patients & 234 & 210 & 444 & F: 3-84 M: 2-83 \\
\hline Total number of stapes interventions, including revisions & 184 & 136 & 320 & $\mathrm{~F}: 17-76 \mathrm{M}: 10-82$ \\
\hline Of these, fixation at the long process of the incus & & & 260 & \\
\hline Of these, fixation at the malleus handle & & & 60 & \\
\hline Of these, primary stapedotomies & & & 228 & \\
\hline Of these, revision stapedotomies & & & 92 & \\
\hline $\begin{array}{l}\text { Total number of cochlear implants, implanted hearing aids, } \\
\text { including revisions }\end{array}$ & 54 & 61 & 115 & F: 3-84 M: 2-74 \\
\hline Fixation of casings & & & 74 & \\
\hline Fixation of casings and electrodes & & & 27 & \\
\hline Fixation of electrodes & & & 14 & \\
\hline Ossiculoplasties and interposition grafts & 3 & 4 & 7 & F:42-77 M:32-83 \\
\hline Coverage of opened mastoid air cells towards the external ear canal & 1 & & 1 & $\mathrm{~F}: 40$ \\
\hline Closure of a fistula of the lateral semicircular canal & 1 & & 1 & $\mathrm{~F}: 52$ \\
\hline
\end{tabular}


Fig. 1 Preparation technique of glass ionomer cement. a SerenoCem ${ }^{\mathrm{TM}}$ packed sterile, the shaking device and the applicator. b The two components of glass ionomer cement in the capsule are thoroughly mixed for $10 \mathrm{~s}$ in the shaking device. c Inserting the capsule containing SerenoCem ${ }^{\mathrm{TM}}$ into the applicator. d Loading the readyto-use semi-liquid glass ionomer cement onto a microtip for use in the field of operation
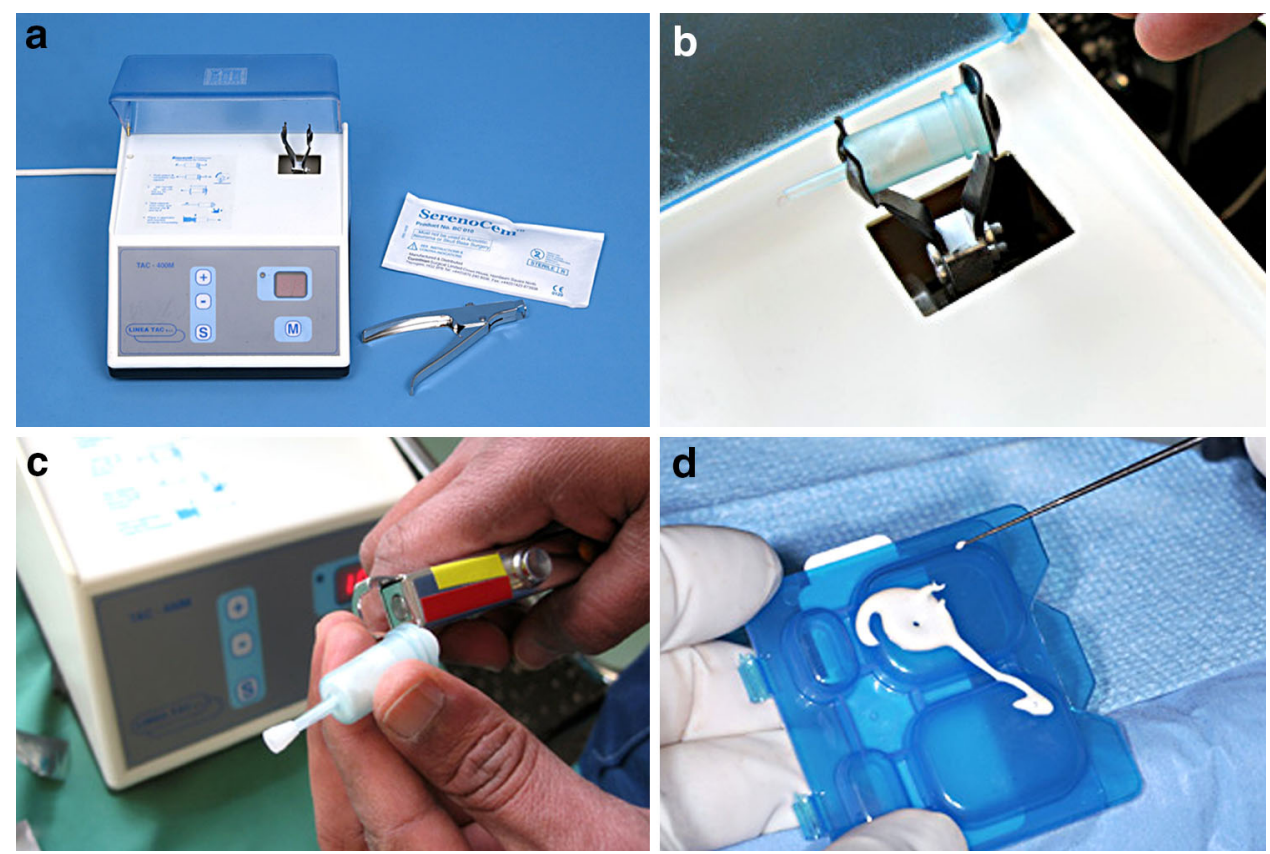
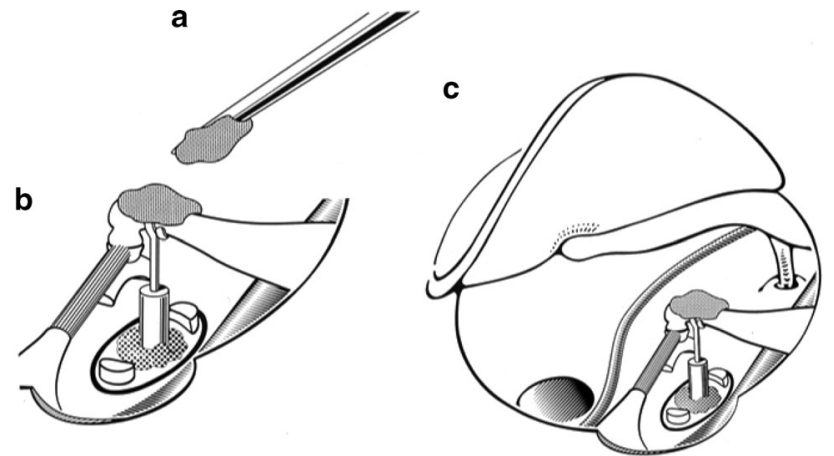

Fig. 2 Application of a drop of glass ionomer cement in stapedotomy for an optimised piston fixation. a Microtip loaded with a drop of semi-liquid glass ionomer cement. b Glass ionomer cement in situ for additional fixation of the metal loop on the long process of the incus, where crimping has been considered insufficient. Note that the stapedial tendon has been preserved in this case. c Overview of the surgical field in a primary stapedotomy on the left side after application of a small drop of glass ionomer cement. The tympanomeatal flap has been elevated

concerned primary interventions as well as complex revision surgery (Figs. 2, 3). Especially in cases of atypical anatomy or revision surgery of the incus, when mechanical metal loop fixation with the crimper alone was deemed insufficient, a small drop of GIC was utilised for additional consolidation of the prosthesis at the incus. In malleus grip stapedectomies, GIC was employed for additional consolidation and stabilisation of the metal loop at the Schuknecht piston or clips of the Häusler MWP piston $\left(\mathrm{Kurz}^{\circledR}\right.$ ) $[21,22]$. Fixing the loop on the malleus handle with cement made it clearly easier to place the piston optimally in the oval window.
In stapes revision surgery (revision not related to the use of GIC), the previously applied GIC could be simply detached from the bone with a tip. Nearly no ossification of cement at the incus or the malleus handle was observed. There was not a single complication in stapes surgery due to GIC in the observation period of 16 years.

In particular, GIC was never associated with significant sensory-neural hearing impairments in stapes surgery (320 cases). The overall incidence of deafness in stapes surgery in our institution during the period of investigation was $1: 250$ cases [21]. Also, there was no incus necrosis noted in the 228 primary stapedotomies where GIC was applied. In comparison, our own overall outcome statistic on primary stapedotomy indicates an incus necrosis risk of $>2 \%[21$, 23].

GIC in cochlear implants and implanted hearing aids

In 115 cases GIC was utilised for fixation of casings (74), casings and electrodes (27) or electrodes alone fixation (14) in cochlear implants and implantable hearing aids (Fig. 4). GIC was important in minimal invasive pericanal cochlear implantation, used for several years as a standard procedure in adult cochlear implantation in Bern [24]. 5 patients $(4.3 \%)$ developed an adverse inflammatory reaction to the cement over a period of 1-6 years after implantation (Fig. 5). These reactions occured after significant mechanical trauma in three of five cases, followed by fragmentation of the cement into loosely detached elements. The small chipped particles of cement caused foreign body reaction, in some cases accompanied by pain, fistulas and expulsion of cement fragments. After careful 

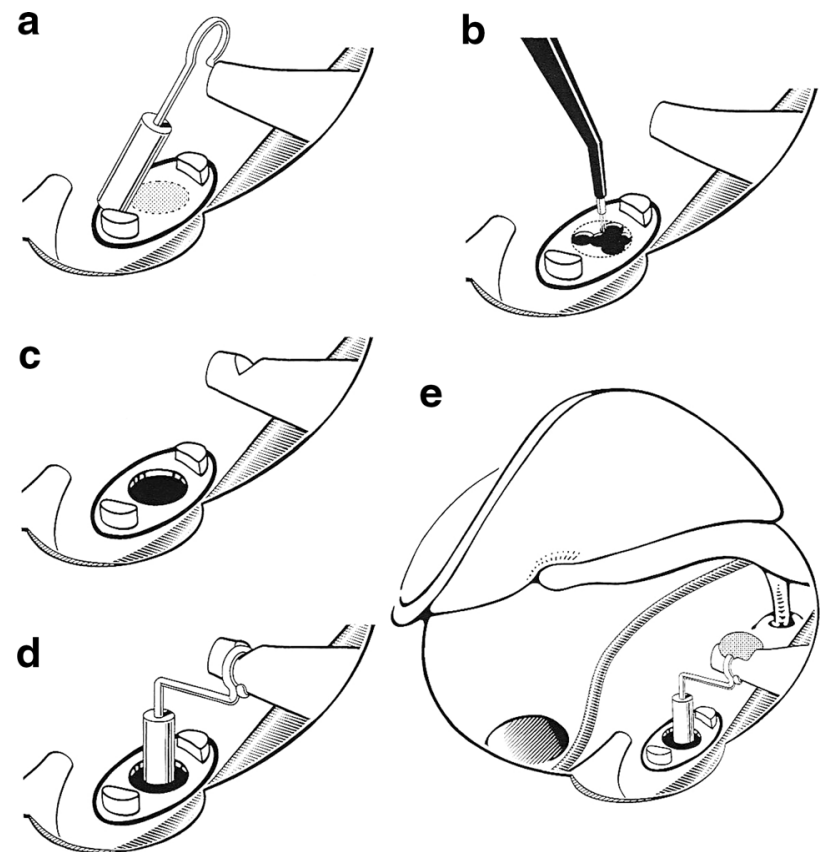

Fig. 3 Application of glass ionomer cement for piston fixation on the stump of a necrosed long incus process in revision stapedectomy. a Initial intraoperative revision situation showing a displaced and extruded piston due to a necrosis of the long incus process. b Reopening of the footplate with the argon laser microhandpiece. c Indent on the incus stump which has been performed with the skeeter microdrill. d Inserted double bent piston crimped mechanically on the incus stump. e Additional consolidation of the metal loop on the incus stump with a drop of glass ionomer cement applied with a microtip

surgical debridement and removal of cement particles which were surrounded by inflammation, the condition healed without further complication in four of five cases. One patient had a persistent inflammatory reaction necessitating explantation of the cochlear implant. Investigation with respect to allergies revealed sensitization to various synthetic products in this patient. After a waiting period of 1 year, a new cochlear implant was inserted fixing the casing by a screwed titanium plate without the use of GIC; the follow-up over 6 years was uneventful.

\section{GIC in ossiculoplasty}

In seven patients, GIC was utilised for bridging a gap between the incus and the head of the stapes. The application was particularly easy and fast. Initially, all these patients had significant hearing gains and air-bone gap closure $(<20 \mathrm{~dB})$. However, in three cases, the hearing gain did not last and after a period of $1-5$ years, revision surgery showed breakage of the cement. Definitive hearing gain was obtained in these cases by classical incus body interposition between the stapes head and the tympanic membrane.

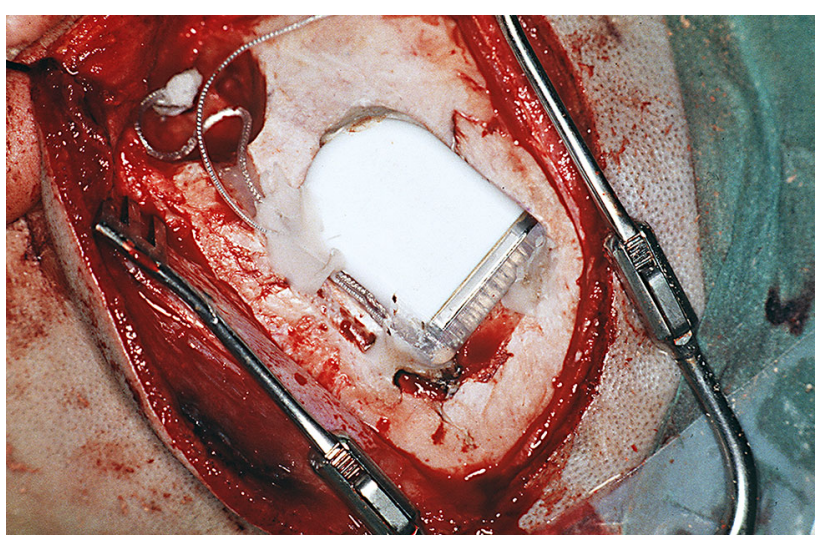

Fig. 4 Retroauricular insertion of a cochlear implant; fixation of the casing and the electrode with glass ionomer cement

Use of GIC for reconstruction of the external auditory canal after opening mastoid air cells and for closure of a fistula of the lateral semi-circular canal

In one patient where opened mastoid air cells towards the external ear canal and in another where a fistula of the lateral semi-circular canal were closed with GIC as a solid air and water tight second layer on a cartilage plate and covered with bone pathé (no direct contact of GIC with the skin of the external ear canal), the follow-up of 6 and 10 years was uneventful.

\section{Discussion and conclusions}

Our long-term study shows that application of small amounts of GIC is suitable and useful in various areas of middle ear surgery when used properly. Complications were rare, and the few problems that we encountered signified no major risk for the patients. Especially in stapes surgery, GIC was shown to be a handy bone adhesive for optimal fixation of prosthetic loops at the incus or the malleus handle without complications. This is also confirmed by others $[11,25,26]$. The fact that there were no dead ears in the GIC series is a positive safety argument. Furthermore, the absence of incus necrosis over the observation time of 5-16 years suggests that optimised piston fixation with GIC may diminish this risk. This should be confirmed by a proper controlled, preferably multicentric study. Based on our hitherto positive experience, we continue to use GIC in stapes surgery on quite large scale that is in about one in three primary stapedotomies and in the large majority of stapedectomy revisions and malleus grip stapedectomies. For cochlear implants and implantable hearing aids, GIC is a technically simple way to fix casings on the bone. Severe complications such as CSF leakage or even intracranial hematoma as reported 

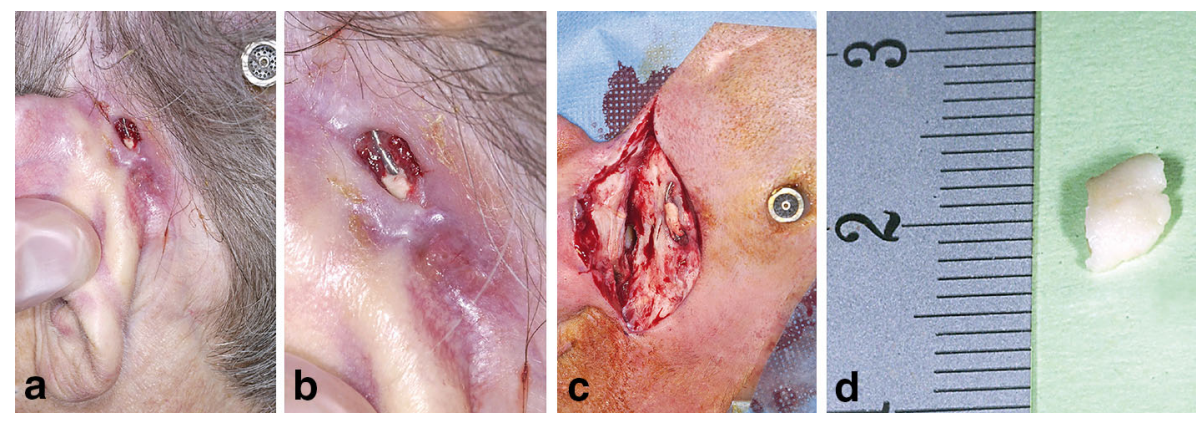

Fig. 5 Partial extrusion of glass ionomer cement particles after head trauma to the site of an implanted DACS hearing aid. a, b Foreign body reactions to glass ionomer cement used for fixation of an

for bone anchored suturing or Dacron mesh application with the need of drilling canals into the skull [28] are avoided. Nevertheless, GIC application in this context can be recommended only to a certain extent. Inflammatory foreign body reactions, mostly due to traumatic fragmentation of GIC, were observed in a few cases $(4.3 \%)$ of our series. Due to these rare but significant complications, we now utilise GIC for implanted devices only in exceptional circumstances. Titanium plates became the standard approach for fixing cochlear implant casings, bone pathé and fibrin adhesives are used for fixation of electrodes. In ossiculoplasty, GIC is technically easy to apply, but may not be always solid enough in the long term, especially for bridging larger gaps [28-37]. The use of GIC as an air and water tight sealing on open mastoid cells and a semi-circular canal fistula was possible when applied as a second layer over cartilage and covered with bone pathé. For the application of GIC in mastoid surgery variable results are reported by others $[38,39]$, probably dependent on indications and the specific application technique. Following the publication of cases of aluminium intoxication encephalopathy, GIC continues, however, to be prohibited in neuro-otosurgery associated with CSF flow [17, 18, 20].

Conflict of interest All authors concur with this submission. The material submitted for publication is not under consideration for publication elsewhere. The authors declare that they have no conflict of interest.

Ethical standards This study has been performed in accordance with the ethical standards.

\section{References}

1. Wilson AD, Kent BE (1972) A new translucent cement for dentistry. The GIC. Br Dent J 15:133-135

2. Kent BE, Lewis BG, Wilson AD (1973) The properties of a glass ionomer cement. Br Dent J 135:322-326

3. George E (1999) Chemical and biological properties of glassionomer cements. Advances in glass-ionomer cements. Quintessence publishing, Chicago, pp 85-101 implanted DACS hearing aid accompanied by the formation of a fistula. c Surgical debridement and removal of cement fragments. d Removed fragment of glass ionomer cement

4. McComb D, Ericson D (1987) Antimicrobial action of new, proprietary lining cements. J Dent Res 66:1025-1028

5. DeSchepper EJ, White RR, von der Lehr W (1989) Antibacterial effects of glass ionomers. Am J Dent 2:51-56

6. Hoszek A, Ericson D (2008) In vitro fluoride release and the antibacterial effect of glass ionomers containing chlorhexidine gluconate. Oper Dent 33:996-1001

7. Wasson EA, Nicholson JW (1991) Glass-ionomer cements in orthopaedic surgery: design of laboratory tests. Clin Mater 8:125-129

8. Higgins WA, Lucksanasombool P, Higgs RJED, Swain MV (2001) Comparison of the material properties of PMMA and glass-ionomer based cements for use in orthopedic surgery. J Mater Sci Mater Med 12:453-460

9. Kraft M, El-Natsheh N, Boenick U (1996) Long-term stability of glass ionomer cement —method and results. Biomed Tech (Berl) 41:23-31

10. Lucksanasombool P, Higgs WA, Higgs RJ, Swain MV (2002) Time dependence of the mechanical properties of GICs in simulated physiological conditions. J Mater Sci Mater Med 13:745-750

11. Hehl K, Schumann K, Beck C, Schottle W (1989) Use of glass ionomer cement in surgery of the incus-stapedial joint. An initial report of experiences. Laryngorhinootologie 68:490-492

12. Geyer G, Helms J (1997) Ionomer cement prostheses in reconstructive middle ear surgery. HNO 5:442-447

13. Müller J, Geyer G, Helms J (1993) Ionomer cement in cochlear implant surgery. Laryngorhinootologie 72:36-38

14. Kempf HG, Issing PR, Lenarz T (1996) Ionomer cement in cochlear implant surgery-applications and long-term outcome. Laryngorhinootology 75:388-391

15. Ramsden RT, Herdman RC, Lye RH (1992) Ionomeric bone cement in neuro-otological surgery. J Laryngol Otol 106:949-953

16. Baier G, Geyer G, Dieler R, Helms J (1989) Long-term outcome after reconstruction of the cranial base with ionomer cement. [Article in German]. Laryngorhinootologie 77:467-473

17. Renard JL, Felten D, Bequet D (1994) Post-otoneurosurgery aluminium encephalopathy. Lancet 344(8914):63-64

18. Hantson P, Mahieu P, Gersdorff M, Sindic CJ, Lauwerys R (1994) Encephalopathy with seizures after use of aluminiumcontaining bone cement. Lancet 344(8937): 1647

19. Lübben B, Geyer G (2001) Toxicity of glass ionomer cement. Laryngorhinootologie 80:214-222

20. Reusche E, Pilz P, Oberascher G, Lindner B, Egensperger R, Gloeckner K, Trinka E, Iglseder B (2001) Subacute fatal aluminum encephalopathy after reconstructive otoneurosurgery: a case report. Hum Pathol 32:1136-1140

21. Häusler R (2004) Advances in stapes surgery. In: Klaus Jahnke (ed) Middle ear surgery. Thieme Stuttgart, New York, pp 95-139 
22. Häusler R, Steinhart U (2007) A new self-fixing and articulated malleus grip stapedectomy prosthesis. Adv Otorhinolaryngol 65:197-201

23. Schmid P, Häusler R (2009) Revision stapedectomy: an analysis of 201 operations. Otol Neurootol 30:1092-1100

24. Häusler R (2002) Cochlear implantation without mastoidectomy: the pericanal electrode insertion technique. Acta Otolaryngol (Stockh) 122:715-719

25. Snik A, Cremers C (2004) Audiometric evaluation of an attempt to optimize the fixation of the transducer of a middle-ear implant to the ossicular chain with bone cement. Clin Otolaryngol Allied Sci 29:5-9

26. Tysome JR, Harcourt J (2005) How we do it: ionomeric cement to attach the stapes prosthesis to the long process of the incus. Clin Otolaryngol 30:458-460

27. de Varebeke SP, Govaerts P, Cox T, Deben K, Ketelslagers K, Waelkens B (2012) Fixation of cochlear implants: an evidence based review of literature. B-ENT 8(2):85-94

28. Serin GM, Cam B, Derinsu U, Sari M, Iar Batman C (2010) Incus augmentation with glass ionomer cement in primary and revision stapes surgery. Ear Nose Throat J 89:589-593

29. Babu S, Seidman MD (2004) Ossicular reconstruction using bone cement. Otol Neurotol 25:98-101

30. Hafiz G (2005) A more reliable method for incudostapedial rebridging ossiculoplasty: bone cement and wire. Adv Ther 22:56-62

31. Dere H, Ozdogan F, Ozcan KM, Selcuk A, Ozcan I, Gokturk G (2011) Comparison of glass ionomer cement and incus interposition in reconstruction of incus long process defects. Eur Arch Otorhinolaryngol 268:1565-1568

32. Kalcioglu MT, Tan M, Fleerakkers J (2013) The use of bone cement for ossicular chain defects. Eur Arch Otorhinolaryngol 270(11):2849-2855

33. Baglam T, Karatas E, Durucu C, Kilic A, Ozer E, Mumbuc S, Kanlikama M (2009) Incudostapedial rebridging ossiculoplasty with bone cement. Otolaryngol Head Neck Surg 141:243-246

34. Bayazit YA, Ozer E, Kanlikama M, Durmaz T, Yilmaz M (2005) Bone cement ossiculoplasty: incus to stapes versus malleus to stapes cement bridge. Otol Neurotol 26:364-367

35. Ráth G, Bauer M, Pytel J, Vóna I, Szanyi I, Lujber L, Gerlinger I (2008) Ionomer cement for reconstruction of the long process of the incus: the Pécs experience. Clin Otolaryngol 33:116-120

36. Ozer E, Bayazit YA, Kanlikama M, Mumbuc S, Ozen Z (2002) Incudostapedial rebridging ossiculoplasty with bone cement. Otol Neurotol 23:643-646

37. Celik H, Aslan Felek S, Islam A, Demirci M, Samim E, Oztuna D (2009) The impact of fixated glass ionomer cement and springy cortical bone incudostapedial joint reconstruction on hearing results. Acta Otolaryngol 129:1368-1373

38. Geyer G, Dazert S, Helms J (1997) Performance of ionomeric cement $\left(\right.$ Ionocem ${ }^{\circledR}$ ) in the reconstruction of the posterior wall after curative middle-ear surgery. Laryngo-Rhino-Otol 111:1130-1136

39. Kuppermann D, Tange RA (2001) Ionomeric cement in the human middle ear cavity: longterm results of 23 cases. Laryngoscope 111:306-309 